\title{
BLOWING UP THE FASHION BUBBLE, OR NINE THINGS WRONG WITH FASHION: AN OUTSIDER'S COMMENT. A CRITICAL ESSAY ON FASHION AS A CREATIVE INDUSTRY
}

\author{
Kristina STANKEVIČIŪTĖ @i] \\ Department of Creative Communication, Faculty of Creative Industries, \\ Vilnius Gediminas Technical University, Traku str. 1, LT-01141 Vilnius, Lithuania
}

Received 15 March 2021; accepted 17 May 2021

\begin{abstract}
The world of fashion has lived in a bubble long before the concept found its way into social networks. Well before the social networks themselves, in fact. The very emergence of fashion as an idea occurred within the bubble of the social life at Palace of Versailles, France, where the notorious Louis XIV sported great interest in the looks of his court in addition to those of his own. The article is an outsider's attempt to have a sober look at the fashion industry that until recently seemed to have maintained the "structure of feeling" of the 17th century Palace of Versailles. Today's social realities, however, put fashion in the state of a shock that probably equals that of the Storming of the Bastille in 1789, even though it is presumably much less sudden.

Written in the manner of the most popular contemporary fashion media format - a bullet list, the text presents a conceptual analysis of the world's second most wasteful yet poisonously attractive industry, critically reflecting on such characteristic values of the fashion field as concept and features, hierarchy, arrogance, resources and philosophy.
\end{abstract}

Keywords: fashion bubble, fashion commentary, fashion concept, fashion industry, rewiring fashion.

\section{Introduction}

A fashion outsider is a tricky concept, for if fashion is understood as trends of garments we choose to wear, no-one can be a fashion outsider (unless they never wear any clothes). Because not wearing fashion is believed to be a fashion choice, too. Yet fashion itself is very eager on excluding its outsiders - the people who are not interested in the newest fashion trends and do not follow the perturbations of the fashion world, i.e. are not fashion professionals in any of the possible meanings. One becomes a fashion professional, or insider, by being educated or working in fashion, which the author of this article is not, having received an education of literary and cultural studies and holding a fashion-unrelated teaching position at university. This lack, however, allows a more observant, even if at the same time a less

*Corresponding author. E-mail: kristina.stankeviciute@vilniustech.lt 
informed, view on the fashion industry that has been quite often compared to an "alternative reality", enclosed in a bubble of self-importance.

The ingenious photography cycle "Fashion in a Bubble" by Melvin Sokolsky (Figure 1), done in 1963 for Harper's Bazaar (Bierend, 2014), perfectly represents the state of fashion mind in relation to its users - back in the 1960s as well as today. An impeccably dressed up model floating in the air high above the city, separated from the tedious banality of everyday, totally absorbed in space of her own style - this concept of fashion shines through since its very inception.

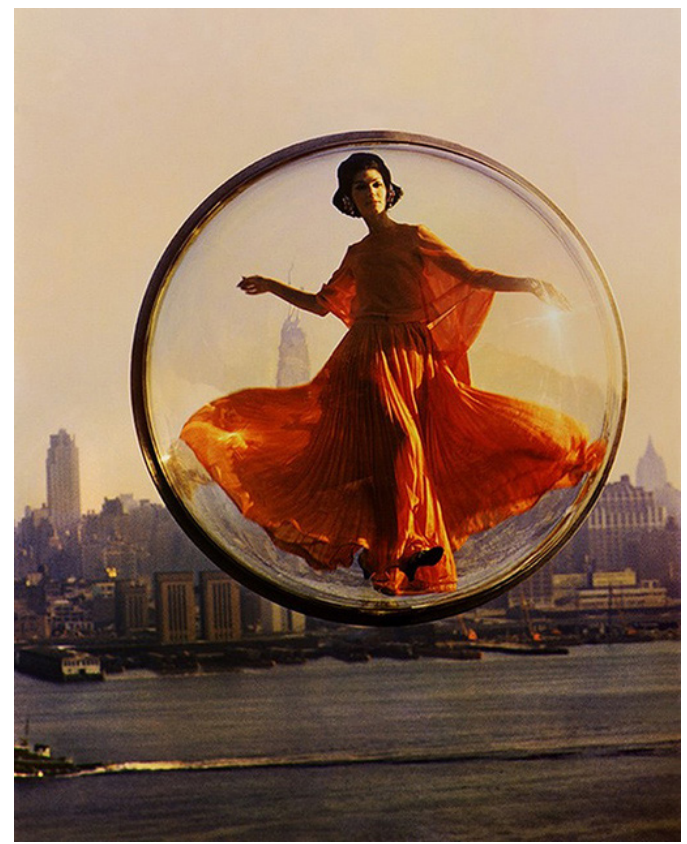

Figure 1. Melvin Sokolsky. From photography cycle Fashion in a Bubble (1963) (source: The Bohmerian: Art, Style and Interior Design (2012))

The concept of fashion as we know it was born in Palace of Versailles, the court of Louis XIV, who "enshrined fashion's importance among the elite by making it an integral part of their etiquette as well as an indicator of their wealth due to its high cost" (Barringer, 2014, p. 21). It was a successful means of financial control - the requirement to dress differently for each formal event was a sure way to keep the courtiers on a short leash: those who wanted to remain important in the court would attend all the events of it, forever having to acquire new garments, and thus falling quickly into debt, with loans granted gracefully by the King himself (Bernier, 1987, p. 103). It was essential to change the fashions often enough to keep the courtiers busy with their dress concerns and no time for considering the meaning(lessness) of it, or, God forbid, a revolt (Bernier, 1987, p. 102). As Barringer puts it, "Louis XIV chose fashion as his means of influence because it both demonstrated the wearer's wealth and took it away, as fashion was inherently expensive, difficult to maintain, and impractical" (2014, p. 22). The dress was seen as a sign of loyalty, serving as an instrument for separating 
the King's favourites from those who were not in his favour; dames who were not fashionable could be expelled from the court (that is one of the possible versions to explain the King's edict of 1668 requiring his courtiers to remain fashionable; there is no certainty, however, whether - and how - the law was enforced) (Barringer, 2014, p. 23). Extending the rules of fashion down onto the middle class in France (any person who was reasonably well-dressed could enter the Gardens of Versailles, France (Mansel, 2005)) formed the primary function of fashion at the time - the marker of status, social position and, naturally, wealth.

This DNA code has remained with fashion until today, even though the field has undergone enormous transformations. Louis XIV formed the idea of fashion in his own image a ruthlessly egotistic personality famous for having said "After me, the flood" (in French: Après moi, le déluge). Regardless of the troubles in the outside world, the social bubble of the Palace of Versailles court could sport the type of dressing that corresponded the whims of the bubble creator's, i.e. the King's, desires. With all the leisure and extravagance available to the French aristocracy of the 17th century, the costume - an instrument of dressing and a servant of appearance - was turned into a separate sphere of activity, producing a new field fashion that quickly turned the tables, becoming a master of its own right.

Fast forward to today, and one finds a pretty much similar bubble, even though its walls have melted to unheard thinness. If you google the word combination fashion bubble, you come up with 359000000 entries or 25 pages of results (data of December 6, 2020), yet on a closer inspection there are only four-to-six finds that do allude directly to what people working in fashion have been hinting for a number of years - that the fashion world lives in a bubble of self-containment, not noticing the actualities around it. One of those articles speaks about the necessity to burst the fast fashion bubble (Holt, 2019), several others ask whether the streetwear bubble will burst in 2019 (Banham, 2019; Brundage, 2018), the remaining two are worried about the fashion-tech bubble (Mulholland, 2019), and the bubble that luxury fashion seems to be lingering in (McCollam, 2016).

The nine ideas below may not be the needles that will burst the fashion bubble, but hopefully will play the role of the legendary little boy who noticed that the emperor's new clothes did not involve any actual clothing.

\section{Concept}

Reading any serious book on fashion will provide one with a definition of the fashion phenomenon as a complex correlation of meanings people find between clothing and the (usually invisible) additional as well as alluring elements of value attached to it (Kawamura, 2018, p. 5). Fashion concept and fashion phenomenon are understood as two separate entities whose existence is determined by their interdependence on each other (Kawamura, 2018, p. 5), with varying constituent elements, such as change (Polhemus, 1994), ambivalence (Davis, 1992), novelty (Barthes, 1997), modernity (Purdy, 2004, pp. 1-20), among others. Like other scholars, Kawamura acknowledges that "it is difficult to give an exact definition of fashion because $[\ldots]$ the meaning and significance of the word have changed to suit the social customs and clothing habits of people in different social structures" (2018, p. 4). 
Yet an average consumer is very likely to define fashion as the change in clothing trends plus self-expression. That is an experiment I did. To be very precise, it was not an average consumer, however, but people transitioning from an average consumer interested in fashion to becoming fashion professionals, which I believe adds importantly to my argument. For three years in a row I asked my first and second year Bachelor of Arts students at a university in Vilnius, Lithuania, to describe in a little essay what fashion meant for them, how they define the concept and what is fashion for, according to them. All in all, I received about fifty essays (mostly a couple of paragraphs each), authored by females of 18-22 years of age, students of Fashion Studies program with the perspective of becoming fashion professionals after graduation. With one or two exceptions, they were all unanimously saying that fashion is a means for self-expression, both for them personally and from a broader perspective. Some would also define fashion as a varied, very colourful and quickly changing phenomenon, a challenging business and an inspiring field of activity. Yet all answers would presume that fashion is first and foremost - and ultimately, I dare say - about clothes rather than anything else.

So it seems that the complexity of the fashion phenomenon is obvious for fashion professionals only. Readers' comments under various articles in fashion media support the idea. As an example of a very critical view on fashion a Dezeen online magazine reader Stefanos S. may be quoted:

"[...] fashion is a pathetic wasteful and elitist industry that's only thinking about money so, practically, nobody can go and enjoy it and hardly anyone can afford to buy it. Today's fashion industry still thinks it's the 1950s. Unacceptable! Fashion houses only care to sell keyrings and perfumes, instead of pleasing an audience in any way" (Hitti, 2020).

The question may arise why this ambivalence is treated as "a thing that is wrong with fashion", when it should perhaps be classified as ignorance on the part of the audience. The following answer is debatable, yet it has its right to exist. Fashion industry is, obviously, one of the most important industries of the world, with estimated value of 3 trillion dollars globally, 2\% of the world's gross domestic product, and 3384.1 million people in the workforce (Fashion United, 2021). These numbers cannot be ignored. Yet seeing the very idea of fashion as obliging and much more than a whimsical caprice is serving the desires of a ruthlessly egotistic master, which may be conceptually understandable in the court of Palace of Versailles, but is really unacceptable in the twenty-first century, for a number of reasons, some of which are listed below. Surprisingly, certain matters on the list seem not to have changed much since the times of Louis XIV.

\section{Features}

Fashion is viewed as frivolous, moody and superficial, therefore it is not taken seriously by a large majority of the Western society, especially the intellectuals (Lipovetsky, 2002, p. 3). The French and the Italian cultures - with the oldest traditions in Europe of attention to appearance and apparel - should be regarded as exceptions. As for France, it may be claimed that the legacy of Louis XIV determines the French attitude to fashion: “[...] it isn't a frivolous 
or trivial industry but an utterly serious one, inseparable from the country's economic health and national identity" (Chrisman-Campbell, 2015). The Anglo-American culture does not seem to share the view, because of a variety of reasons that the space of this essay does not allow to discuss. The scepticism of the general audience about fashion's overrated importance is visible in many forms of popular culture; popular films would be the best known examples. The likes of Prêt-à-Porter (1994, directed by Robert Altman), Zoolander (2001, directed by Ben Stiller), The Devil Wears Prada (2006, directed by David Frankel), among others, reveal the attitude to the fashion world as an exaggerated, self-centered and self-absorbed space an attitude that may be considered dominant in the "mainstream" Anglo-American society.

Motives for the scepticism vary. The designer Peter O'Brien, for example, thinks the word fashion is overused and very often relates more not to fashion in the traditional sense of the word, but shopping, rather. "The masses have become used to buying very, very cheap clothes, and very often, what's called fashion isn't" (MacCabe, 2013).

The very field of fashion has been expanding exponentially to include the ever-growing number of categories like luxury fashion, streetwear, tailored wear, fast fashion, independent brands, etc. It only adds to the confusion, especially for an outsider. As a business, fashion is very far from being trivial, it is a highly sophisticated and well-organized industry. Yet the superficiality of the concept behind it is acknowledged by industry representatives themselves. The "rag-trade" is a common denominator of fashion one can come across easily in the British fashion media. The Irish Times fashion reviewer Laura Cunningham admits that being a fashion editor is still regarded as light-weight journalism "as if it's a joke of sorts", and she has second thoughts about "writing about dresses and skirts while there are a lot more important things in life” (MacCabe, 2013).

\section{Function}

It may seem that fashion should have come a long way since the times of Louis XIV, yet as a matter of fact, it has maintained its main purpose - that of a status marker. Many contemporary critics and theorists, like Davis (1992), for example, would argue that fashion has liberated itself from this fascist function, and has opened up to every single individual who is willing to practice it. Fashion insiders claim that fashion has become the expression of one's style and that the fashion-conscious have access to a myriad of styles at a great variety of prices (Corner, 2014, p. 25), so fashion has become accessible as never before. Yet this naïve belief may be only shared by those who do not actually practice fashion themselves. Anyone who has seriously tried to be fashionable for at least, say, one year, knows how much fashion costs - not so much in terms of finance, but effort, time, interest, and occasion, finally - fashion is irrelevant when you stay at home, you need an event that takes you out just to practice that fashion (and, yes, social networks have been an extremely favourable help in this regard). You have to have the privilege of all of the above to be able to practice fashion as a hobby, or to have a fashion job, which puts you in a privileged position automatically.

The concept of function returns us again to the question of what fashion is. If we perceive it as a combination of certain trends that change periodically, it will become obvious that few individuals may practice it freely, as there are few individuals who can wear ALL trends 
with becoming. On the other hand, seeing fashion as an open field of trends that anyone may pick up for interpretation poses doubt about the very meaning of the fashion phenomenon: if anybody may do anything they like with any trend, i.e. to match their personal style rather than a popular trend, why do we need fashion for in the first place? If there is no audience to care about the fashion dictate, then what is the meaning of fashion at all?

The idea that fashion has died and style is taking over has been around for some time yet. Fashion forecaster Lidewij Edelkoort announced in 2015 it is "the end of fashion as we know it" (Fairs, 2015). If that is true, should we understand that the whole fashion system with the haute couture houses, fashion weeks and fashion magazines - both paper and digital - are merely convulsions of a decaying body?

\section{Hierarchy}

The outsiders who do not work in fashion would probably presume that, especially today, fashion is very relaxed and one can wear whatever one likes, for not many seem to care. They may be even right. The outsiders might also presume that one's position in fashion hierarchy is related to one's aesthetic taste and fashion knowledge, and would be right again, perhaps. Until recently, the spread of fashion would happen from designer to the customer via the fashion magazine, which formed the basic structure of the fashion hierarchy. The fashion magazine would be the guru of fashion information that collected fashion news from designer ateliers and haute couture houses or high street brands and spread it further to the customers. With the emergence of the Internet the process was challenged first by fashion bloggers, who dared to express their own unsolicited and absolutely independent opinion on everything from trends to the catwalk and designers themselves. They could be "anyone, could publish anything they wanted, and [they] couldn't be threatened by the withdrawal of advertising or access" (Bradford, 2014, p. 199). Discussing the blogging phenomenon in her book Fashion Journalism in 2014 Bradford provides an insight that should be seen as the key to the relation between fashion and the outside world - the actual needle that is able to blow up the fashion bubble. "Bloggers are, like journalists, telling a story about fashion", says Bradford, "but it's a different kind of story - not one based on technical knowledge or informed criticism, perhaps, but rather one where fashion meets real life" (2014, p. 199).

The call of longing for reality in fashion customers was answered by social networks that put the final nail into the coffin of fashion's habitual hierarchy. Or so it seemed at first sight, when everybody - not only those who enjoyed writing about fashion - could become a star in the new profession of influencer. But it only lasted a moment, and new hierarchies were quickly formed both in social networks in general and those related to fashion in particular. It is obvious that fashion influencers did not actually reverse the fashion hierarchy principle, i.e. fashion is still attributed to the elite, but the concept of the elite has been drastically transformed. The new elite are the "networkers" (Castells, 1996, p. 246), skilled and self-reliant, functioning mainly in the Net, able to exercise power and dominate over others because of their exclusive access to, influence over and control of communication. Thus, the new fashion elite are the Instagram influencers with thousands of followers, and their place in the fashion hierarchy is related to the number of their audiences: the wider access to the net they have, 
the higher place in the hierarchy, and the closer to the catwalk is their chair in a fashion show. Not digital - physical show, of course. And if the previous fashion hierarchy did seem tolerable to an extent (not everybody has good taste in clothes, and people should have authorities to learn from), the current elites often seem suspicious, as their influence does not necessarily relate to aesthetic tastes, but to communication power, which does not refer to fashion at all.

\section{Taking itself too seriously}

In one of his interviews Karl Lagerfeld, asked about the importance of fashion, said that it should not be overemphasized, but the interview today is quite difficult to come by ${ }^{1}$. Nevertheless, this relaxed view on fashion does not seem to be shared by many of its professionals. True, irony and satire are not alien to the fashion world, and the names of Viktor \& Rolf, Jeremy Scott, Demna Gvasalia and Virgil Abloh are noted as proof (even though the two latter's ironic views receive really mixed reactions). Still, fashion more often than not mistakes its instrumental function of dressing a body - yes, in a new, unconventional or unexpected kind of way - for the function of dominance. When you hear that a designer had a single handbag flown by a helicopter across a whole country to accompany a model on the catwalk, just because any other of the ones she had at hand would NOT do in any way (a true story told by the then-assistant of that world-famous Italian designer), there are a few ways to digest this type of information. You either take it as top professionalism that would not tolerate a minutest mistake, or you apply your common sense and think it is going much too far in the pursuit of perfection that is getting dated in the light of global warming, global pollution and other environmental concerns (the mentioned handbag was not even used for the mentioned show in the end).

In her iconic speech on the importance of fashion Miranda Priestley, the alleged impersonation of the iconic Vogue Editor-in-Chief Anna Wintour in the iconic film on the importance of fashion The Devil Wears Prada snaps out to her new, incompetent and fashionsceptical assistant that the "stuff" the young employee considers inconsequential - i.e. a sweater colour -

"represents millions of dollars and countless jobs and it's sort of comical how you think that you've made a choice that exempts you from the fashion industry when, in fact, you're wearing the sweater that was selected for you by the people in this room from a pile of stuff" (Marchand, 2016).

And considered in business terms it would be difficult to argue about the importance of the fashion industry to the world economics. But then again - viewed from the perspective of today's urge for sustainability, circular economy and the challenges of overproduction, the whole point that Miranda Priestley is making is really comparable to the above example of the Italian handbag. We may calculate how many people were employed for fetching the handbag to the show, and how much tax was paid to achieve that, but we may also ask the nasty question of whether the investment was adequate?

\footnotetext{
1 "Fashion is fun and you can't really take it too seriously. Frivolity must be an integral form", Lagerfeld said in 1975 during his conversation with André Leon Talley, who was doing the interview for the Interview magazine after Lagerfeld was appointed head creative designer at Chloé (Talley, 2020, p. 25).
} 
The indispensability of fashion stands on the shoulders of fashion victims: the underpaid women and children in sweatshops, the polluted water and cloth-crammed landfills, the overuse of resources and overpriced poor quality. Not much to be so proud of, dear Miranda.

\section{Arrogance}

Privilege and hierarchy stimulate one rather unpleasant quality that the fashion world abounds in - arrogance. And it is not only the disdainful top-down look of the fashion people upon those who are not fashionable (that could be understood, as it definitely hurts an aesthetic eye to observe an outfit that is not matched well). It is a much more pervasive arrogant attitude, best expressed through the same character of Miranda Priestley of The Devil Wears Prada, a film that revealed the passions of the fashion world to the general audience in an amusing yet thought-provoking way. The fact that the atmosphere portrayed in the film is not much of an exaggeration is confirmed by reports of fashion expats, like the former Lucky magazine (a Condé Nast media company publication on fashion and lifestyle issued from 2000 to 2015) Editor-in-Chief Kim France, who, being one of Condé Nast's top performers (Callahan, 2018), suffered from the overwhelming feeling of not belonging: "There was simply no way to ever feel polished enough", she wrote. "I always felt a distinct spirit of exclusion the moment I walked in the door" (France, 2016).

The competitive atmosphere that France describes is characteristic to many fields other than fashion, and the "connoisseur arrogance" is not exceptional to fashion either - they are practiced by most professionals in most spheres. The issue with fashion is that, differently from other professional fields, it is very manifest - you can see at once whether a person knows anything about fashion or not (while it would definitely take you a while to discover whether someone is educated in arts, mathematics or medicine).

Here lies the paradox - we as audience do not have the ambition to understand all (or much) of the details about the creation of a theatre-play or an artwork, not to mention nuclear physics or surgery. While with fashion, as it tends to be equalled to the methods of dressing, everybody seems to have the right to sport it. Thus, the haughtiness of fashion professionals is much less readily tolerated than that of medical doctors or, say, information technology specialists.

It must be admitted that fashion has been trying to make up for the sin of arrogance for quite a while now. Inclusivity is one of the new trends that has been taken up into a number of fashion elements. Fashion weeks issue strict requirements for participants how many catwalk models should be of what colour, brands do their best to embrace the largerthan-M-size audiences, and the movement against age discrimination has grown into "silver economy", not to mention thousands of blogs and social media accounts created by the senior (usually) ladies that promote the joy of life in the form of stylish appearance (my favourites, along with Iris Apfel, are Lyn Slater Accidental Icon and Dorrie Jacobson's blog Senior Style Bible).

It seems to be a win-win situation, as employing senior models and paying attention to varieties create positive evaluation of brands, while the audience groups in question (the elderly, people of colour, handicapped people etc.) may find consolation and support in the 
images of their peers. Yet the problem with inclusivity lies not so much in the communicative messages that fashion exhales, but also in the products themselves, balanced for the young, the sexy and the lovely. It was from Iris Apfel where I heard it first - she had expressed the wish to open up a shop named The Sleeve for selling clothes with sleeves. Because, she said, it is impossible to get a blouse or a dress that has them (Rankin, 2012). You may photograph as many old people and people of colour for your marketing as you like, but if your brand does not produce clothing that fits most age groups and most bodies, you are not inclusive.

\section{Egotism}

The above takes us directly to another fashion paradox - its unsympathetic quality that is at the same time one of the main reasons of its attractiveness - its unique egotism, or selfcenteredness. In the court of Louis XIV as well as in the ateliers of the early French designers Paul Poiret, Madeleine Vionnet etc., fashion is an elitist occupation, a passion that does not care about anything except itself. It would be difficult to argue with the view that haute couture fashion is definitely a form of art, so its not being practical or sometimes even wearable does not actually bother. It is fashion for fashion's sake, and the designs of Gareth Pugh and the like do not raise doubts that such type of creation deserves admiration like any other form of art. The discussion on how much is fashion an art in general, however, cannot be squeezed into the limits of this text. Yet some words must be said about the necessity to draw the boundary between fashion as art that does not have any practical function and serves as an instrument for expressing artistic ideas through the medium of textiles/clothing/accessories, and fashion as an instrument for dressing people (when "dressing" means covering the human body with adequate clothing for protection from nakedness and environment and at the same time responding to the spirit of the zeitgeist in the choice of types of materials, colours, shapes, texture, length, etc.). The zeitgeist Palace of Versailles did not involve much of the latter in terms of adequacy - the robes of French aristocracy of the 17th century required several people's help to be put on as well as to be taken off. A sophisticated costume demonstrated that its owner had enough wealth to hire people to help him/her dress up, while wearing such dress indicated the person's belonging to the highest social rank exempt from any physical work. More than two hundred years later the American sociologist Thorstein Veblen described it as a practice of "conspicuous consumption" (1918), exercised by those who have plenty of leisure time - the leisure class that can afford clothes unsuitable for any respectable kind of work, because it shows the rest of the world that the wearer does not have to work in the first place.

Admittedly, fashion has been developing in the direction of democracy ever since its early days, but only in ways convenient for itself, not the "final customer". For example, it took ages to get rid of the corset - the perfect symbol of fashion in Louis XIV "style" as one of the most artful and definitely the most harmful element of the female costume in Western history, but it was not fashion who did it. It was World War I. It returned quite promptly after the war was over, and women today must thank Coco Chanel for (among other things) getting rid of the corset for good (though it was Poiret who did it first).

It is rather obvious that dress is not as important as most of us - especially those who adore shopping - would like to believe. In the face of a catastrophe such as war or plague 
fashion remains an instrument for clothing the body - to the great chagrin of fashion professionals and their most eloquent attempts to convince the consumer to the reverse. We do not need to go very far back in history, it is enough to look at the facts of the current pandemic, with sales of most brands falling drastically down (except sportswear and homewear).

\section{Resources}

When Louis XIV designed his idea of the fashionable, planet Earth was still to a quite large extent a strange territory for most of the Europeans, and the problem with the resources was that they were not available due to lack of knowledge or their absence in a particular area (quality lace, for example, was produced only in Venice, Italy (Goldenberg, 1904, p. 10)). The constant change that the concept of fashion is constructed around is based on the idea of inexhaustible resources that cannot fail, backed up with the industrial economy of production for the sake of production. The emergence of fast fashion may be regarded as the final chord of the industrialization era that puts production and consumption above everything else. The fashion production cycle in the last decade has grown from two collections per year (springsummer and autumn-winter) to five or six, while the fast fashion shops (like Forever 21 and ZARA) provide new arrivals every few weeks (Forrester, 2017) instead of once a season.

A circular economy is the freshest goal of today, with sustainability as the newest trend, which is a very welcome way of doing things. Fashion recycling, however, is not a panacea that some believe it to be. Remy et al. writing for McKinsey Sustainability state that

"current technologies cannot reliably turn unwanted apparel into fibers that could be used to make new goods. Recycling methods such as shredding or chemical digestion work poorly. And there are not markets large enough to absorb the volume of material that would come from recycling clothes. As a result, for every 5 garments produced, the equivalent of 3 end up in a landfill or incinerated each year" (2016).

The other question that keeps creeping back is how genuine the sustainability trend is? How much can we trust those brands who declare their sustainability goals yet keep producing clothes at the same rates they did before? The best-known example here is, of course, $H \& M$ that has been "aggressively marketing itself as a sustainability leader - with collections dubbed 'conscious' and a commitment to using sustainable materials all splashed in the media" (Well Made Clothes, 2018). Closer investigations have revealed that only 5-10 percent of collected clothing is recycled into fibres that can ultimately be made into new clothes. Yet the real burning issue here is not the percentage of recyclable textiles, but the one that sustainability-oriented minds have been asking since the early days of fast fashion: how sustainable is it to produce as much clothing as a fast fashion company, such as $H \& M$, does and then try to make up for it via recycling (Well Made Clothes, 2018)? It is - rightfully - claimed that the fast fashion business model is wasteful by design because it requires cheap (usually unethical) labour, results in poor quality, and the imitational recycling campaigns are made not "to work towards a solution to the incredible wastefulness of the clothing industry but to give customers a way to feel morally righteous about buying more than what they need and treating clothing as disposable" (Otte, 2019). 
Obviously, recycling textiles is a solution that is sustainable only in part, either for fast fashion or for fashion in general (also see Fletcher, 2008). The single truly sustainable solution for fashion today is making less fashion production. Not fast fashion - all fashion industry.

\section{Philosophy}

Not many books discuss fashion philosophy, even though quite a few readers have been published recently that review the ideas of various thinkers and philosophers about fashion. At least two are interesting as providing a very full perspective on the philosophy of the fashion phenomenon (The Rise of Fashion: A Reader (Purdy, 2004) and Thinking through Fashion: A Guide to Key Theorists (Rocamora \& Smelik, 2015, also see Wolfendale \& Kennett, 2011)). The only contemporary book that deals with fashion philosophy directly is by a Swedish author Lars Svendsen, who claims that the essence of fashion is change. He defines the nature of fashion as transient: "[T]here is a central insistence on radical innovation, a constant hunt for originality. Fashion is only fashion insofar as it is capable of moving forwards" (Svendsen, 2006, p. 31). Svendsen believes that fashion moves in cycles of

"spaces of time from when a fashion is introduced to when it is replaced by a new one, and the principle of fashion is to make the cycle - the space of time - as short as possible, so as to create the maximum number of successive fashions" (2006, p. 31).

The ideal fashion in this way would "only last a moment before it was replaced by a new one" (Svendsen, 2006, p. 31). The social media seems to have brought the process to nirvana - with social networks it is possible to change the fashion not once a day, but virtually once a minute, if you have adequate reserves of images in supply.

The state of continual change did not, however, bring happiness but only complicated the market, the consumer as well as fashion itself, abusing the resources, increasing pollution and oversaturating the supplies (also see Bauman, 2000). As I was saying, fashion is believed to be dying, and style is coming forward to replace it. Thus we return to the same question of purpose - again. What is fashion for? It used to be the change that drives fashion forward, and that change was the signifier of being modern, wealthy, having good taste. If we eliminate change because we must think sustainably - what is fashion about then?

\section{An afterword on fashion's creativity}

The criticism expressed in the above text applies to what should be regarded as the "established fashion system", with its markers such as haute couture, fashion houses, seasonal fashion shows, star designers versus other designers, and many more. Fashion today, however, has expanded well beyond the boundaries of high-street brands and prestigious fashion houses, becoming one of the most influential among the creative industries and one of the most important cultural voices. If the cool kids of the 1990s wanted to become a music band player, today they want to make it in the fashion world (Rabkin, 2021a). As Lipovetsky has put it, "fashion is in the driver's seat" (2002, p. 6). Its new forms, such as streetwear and sportswear, have brought new creative players into the field which seem to redefine the notion of the fashion bubble. Nevertheless, nearly all of the nine principles of fashion's modus operandi discussed above have remained almost intact. 
After this critical essay was accomplished, several new articles occurred in fashion media, mainly by veteran fashion writer and critic, as he is called, Eugene Rabkin, that in one or another way confirm the opinion expressed in the above text.

In his op-ed piece "Read This before You Decide to Work in Fashion" Rabkin (2021b) notes the omnipresence of fashion's hierarchy and conservatism, its arrogance (the you-can'tsit-with-us mindset, as he puts it), false concern with sustainability and real interest in selling more, elitism and toxicism as the dominant characteristics of fashion today. In "Don't Do It Yourself: Chances Are, You Aren't Gonna Make It in Fashion” (2021a) the writer warns against the deceptive lure of quick money that establishing a streetwear brand seems to offer. The main concern of Rabkin could be identified as finding a balance between the "established fashion system" and the perception of the absolute necessity for it to regenerate following the tide of the time. The processes of social change, brought about by social networks, have not only had impact on the processes of democratization that have affected fashion, among other creative industries. The networking society that Manuel Castells (1996) described at the end of 20th century challenges the traditional social hierarchy, putting the hierarchy of communication first. The very concept of authority has been affected as well, with authority acquiring new conceptual planes of reference. Authority in creative industries is defined today not by education, training, experience, tradition, novelty. It is defined by authenticity that does not aim at creating anything new, but at interpreting "existing ideas, trends, styles and looks by making them slightly different than before" (Andjelic, 2021). Ana Andjelic terms it "amateurism", claiming that amateurs are

"free to endlessly interpret culture, heritage and brands because they're not bound by tradition, education, training or an established way of doing things. They comfortably reside in the domain of their own geekiness and play with things for fun and their own pleasure and status in their community" (2021).

Brands are finding themselves irrelevant and try to catch up with the times by adapting to the style of the young who do not value the solidity and mastery of the handicraft anymore but are ready to pay ridiculous sums of money for irrelevant fashion objects that they will only wear for an Instagram photo. Rabkin believes that this state of affairs is due to two major phenomena:

"the rise of a type of celebrity who possesses no discernible skills (thanks to reality television and social media), and a democratization of the means of production that has allowed for unprecedented amateur cultural output" (2021a).

Networking as the dominant social arrangement should be added as a third reason for the social change in question, I believe. The networking society provides more opportunity for action (and amateur creativity) for everyone (even though Castells has proven that certain limitations exist in the network, effectively preventing its members from equal opportunities) despite their professional preparation. Therefore, though Rabkin seems to be right to emphasize professionalism, education and other traditional qualities important for success, warning against the $I$ can do this too mindset, his advice sounds like grumpy nostalgia for the old ways. The amateurs trying their hand at streetwear may be regarded in this light as daring revolutionists who attempt to resist the system by challenging its rules: achieving success outside and despite the fashion establishment. Creating new forms of operation for resistance against the omnipresent authority of the fashion system hierarchy after the old ones have been commodified, as Fiske 
(2011) would probably see it. Yet on the other hand, the forms themselves - new streetwear brands, in this case - do not actually resist but duplicate the commodification, multiplying the amount of clothing produced but not improving in any way on fashion's deficiencies. Most new successful streetwear brands (their number, according to Rabkin, is very small) are either incorporated into the fashion system or run in parallel universes with it, with little to no impact on its overall functioning. So in the end, Rabkin seems to be absolutely right in doubting whether the democratization of access to communication through the new media and different modes of fashion like streetwear will definitely bring about significant change: "it remains to be seen whether we are not simply exchanging one power structure for another - it's a historical truism that people in power will inevitably abuse it" (Rabkin, 2021b). It also remains to be seen whether the small innovative brands and designers, who seem to have the potential to reform the industry, will manage to be heard against the loud clatter of the simulated sustainability concerns of fashion conglomerates. The hierarchical and protectionist fashion system does not seem to be willing to change its course from its main concern - that of profit - to anything else. Emotion, creativity, transparency, openness to variety of all of its forms is what may save fashion and its users, steering it clear from toxicity and disappointment.

\section{Conclusions}

For the final note it must be said that the fashion system realized the absolute necessity for change even before the pandemic of 2020, with its brightest minds attempting to introduce certain transformations which testify that some of the nine notions discussed in this article are really burning issues both from the industrial and the conceptual points of view. One of the most important fashion media players, The Business of Fashion (2020) platform, has published an address to the global fashion community marked with the hashtag \#rewiringfashion, inviting fashion colleagues, first, to review the global fashion calendar and return to the clearly defined two-season structure, and second, to increase sustainability through "less unnecessary product", among other things. Though it is difficult to find the date of the address, it has been signed by almost 2200 supporters with brands such as Erdem, Isabel Marant, Missoni and Mary Katrantzou among them. It is obviously a very caring initiative, even if it is not clear at all what methods would be used to make the noble idea turn into flesh. Nevertheless, The Business of Fashion seems to be one of the most concerned with encouraging the discussion on the current fashion system and its adequate renewal.

I would like to finish this piece of conceptual fashion criticism with an insight by the Dutch designer Dries van Noten who spoke on The Business of Fashion annual conference The Voices 2020: "We have to bring emotion back to fashion. Fashion is about something that is beautiful, not so much about business as it has become". Hopefully, emotion can free fashion from the arrogant legacy of Louis XIV and open up new conceptual meanings of it.

\section{Acknowledgements}

I am sincerely grateful to Dr Nuno André Amaral Jeronimo and Arnoldas Remeika for their valuable insights and their comments on this essay. Their encouragement and support has been highly appreciated. 


\section{References}

Andjelic, A. (2021). The reign of the great fashion amateur. Highsnobiety. https://www.highsnobiety. $\mathrm{com} / \mathrm{p} /$ reign-great-fashion-amateur/

Banham, T. (2019). Will the streetwear bubble burst in 2019? Fashionbeans. https://www.fashionbeans. com/article/will-streetwear-bubble-burst/

Barringer, S. (2014). Louis XIV's use of fashion to control the nobility and express power. Primary Source, 4(2), 21-25.

Barthes, R. (1997). The fashion system. University of California Press.

Bauman, Z. (2000). Liquid modernity. Polity Press.

Bernier, O. (1987). Louis XIV: a royal life. Doubleday.

Bierend, D. (2014). In the '60s, models floated through Paris in Bubbles. Wired. https://www.wired. com/2014/02/throwback-thursday-retro-fashion-retrofuturism-collide-1963-bubble-series/

Bradford, J. (2014). Fashion journalism. Routledge. https://doi.org/10.4324/9780203130865

Brundage, D. (2018). Is the streetwear bubble about to burst? Highsnobiety. https://www.highsnobiety. com/p/hype-bubble-streetwear-bubble-burst/

Callahan, M. (2018). Fashion is dead and there's no coming back. New York Post. https://nypost. com/2018/01/20/fashion-is-dead-and-theres-no-coming-back/

Castells, M. (1996). The information age: economy, society and culture. Vol. 1: The Rise of the Network Society. Blackwell Publishing Ltd.

Chrisman-Campbell, K. (2015). The king of couture: How Louis XIV invented fashion as we know it. The Atlantic. https://www.theatlantic.com/entertainment/archive/2015/09/the-king-of-couture/402952/

Corner, F. (2014). Why fashion matters. Thames and Hudson.

Davis, F. (1992). Fashion, culture, and identity. The University of Chicago Press. https://doi.org/10.7208/ chicago/9780226167954.001.0001

Fairs, M. (2015). "It's the End of Fashion as We Know It" Says Li Edelkoort. Dezeen. https://www. dezeen.com/2015/03/01/li-edelkoort-end-of-fashion-as-we-know-it-design-indaba-2015/

Fashion United. (2021). Global fashion industry statistics - international apparel. https://fashionunited. com/global-fashion-industry-statistics/

Fiske, J. (2011). Understanding popular culture. Routledge. https://doi.org/10.4324/9780203837177

Fletcher, K. (2008). Sustainable fashion and textiles: design journeys. Earthscan Publications Ltd.

Forrester, K. (2017). Re: how often do fashion brands release collections yearly? Quora. https://www. quora.com/How-often-do-fashion-brands-release-collections-yearly

France, K. (2016). The holiday lunch. https://medium.com/@kimfrancenyc/the-holiday-lunch-68cd$16 \mathrm{e} 6 \mathrm{db} 85$

Goldenberg, S. L. (1904). Lace, its origin and history. Brentano's.

Hitti, N. (2020). Gucci abandons "Worn out Ritual" of seasonal fashion shows. Dezeen. https://www. dezeen.com/2020/05/29/gucci-seasonless-fashion-news/

Holt, B. (2019). Could the fast-fashion bubble be about to burst? The Telegraph. https://www.telegraph. co.uk/fashion/style/could-fast-fashion-bubble-burst/

Kawamura, Y. (2018). Dress, body, culture. Fashion-ology: an introduction to fashion studies. J. B. Eicher (Series Ed.). Bloomsbury Publishing Plc. https://doi.org/10.5040/9781474278515

Lipovetsky, G. (2002). New French thought. The empire of fashion: dressing modern democracy. Th. Pavel $\&$ M. Lilla (Series Eds.). Princeton University Press.

MacCabe, R. (2013). Is fashion frivolous or fabulous? The Irish Times. https://www.irishtimes.com/lifeand-style/fashion/is-fashion-frivolous-or-fabulous-1.967764 
Mansel, Ph. (2005). Dressed to rule: royal and court costume from Louis XIV to Elizabeth II. Yale University Press.

Marchand, Ch. (2016). Meryl Streep's speech from "The Devil Wears Prada” is a load of rubbish. PostConsumer Reports: Thoughts on Art and Faith Written after Consumption. The Blog of Chris Marchand. http://www.postconsumerreports.com/2016/03/meryl-streeps-speech-from-devil-wears.html

McCollam, C. (2016). Has global luxury fashion hit a bubble? Social Media Today. https://www.socialmediatoday.com/social-business/has-global-luxury-fashion-hit-bubble

Mulholland, S. (2019). Is the fashion-tech bubble going to burst? Vogue Business. https://www.voguebusiness.com/companies/fashion-tech-ipo-bubble-realreal-farfetch

Otte, M. (2019). H\&M’s Green initiative is a scam. https://medium.com/@ameliaotte/h-ms-green-initiative-is-a-scam-73bc23fe 94

Polhemus, T. (1994). Street style: from sidewalk to catwalk. Thames and Hudson.

Purdy, D. L. (Ed.). (2004). The rise of fashion: a reader. University of Minnesota Press.

Rabkin, E. (2021a). Don't do it yourself: chances are, you aren't gonna make it in fashion. Highsnobiety. https://www.highsnobiety.com/p/make-it-in-fashion/

Rabkin, E. (2021b). Read this before you decide to work in fashion. Highsnobiety. https://www.highsnobiety.com/p/read-decide-work-fashion/

Rankin, S. (2012). “What we learned from Iris Apfel (and her talk at Sotheby's). Refinery29. https://www. refinery29.com/en-us/iris-apfel-dara-caponigro-lecture

Remy, N., Speelman, E., \& Swartz, S. (2016). Style that's sustainable: a new fast-fashion formula. McKinsey Sustainability. https://www.mckinsey.com/business-functions/sustainability/our-insights/stylethats-sustainable-a-new-fast-fashion-formula

Rocamora, A., \& Smelik, A. (Eds.). (2015). Thinking through fashion: a guide to key theorists. I.B. Tauris. https://doi.org/10.5040/9780755694785.ch-001

Svendsen, L. (2006). Fashion: a philosophy. Reaktion Books.

Talley, A. L. (2020). The Chiffon trenches: a memoir. Ballantine Books.

The Bohmerian: Art, Style and Interior Design. (2012). Art finds: "Fashion in a Bubble" by Melvin Sokolsky. https://www.thebohmerian.com/2012/04/fashion-in-a-bubble-a-art-photo-series-by-americanphotographer-melvin-sokolsky/

The Business of Fashion. (2020). \#rewiringfashion. https://www.rewiringfashion.org/

Veblen, Th. (1918). The theory of the leisure class: an economic study of institutions. B. W. Huebsch.

Well Made Clothes. (2018). The truth about HM's recycling initiative. https://wellmadeclothes.com/ articles/TheTruthAboutHMsRecyclingInitiative

Wolfendale, J., \& Kennett, J. (Eds). (2011). Philosophy for everyone. Fashion: Thinking with Style. F. Allhoff (Series Ed.). John Wiley \& Sons Ltd. https://doi.org/10.1002/9781444345568 